\title{
Correction to: Tropical cyclone: expressions for velocity components and stability parameter
}

\author{
Indrajit Ghosh ${ }^{1}$ (D) Nabajit Chakravarty ${ }^{2}$
}

Published online: 19 October 2018

(c) Springer Nature B.V. 2018

\section{Correction to: Natural Hazards https://doi.org/10.1007/s11069-018-3477-7}

The original article was published with an error in section "5 Results and discussion". To correct this, the authors would like readers to know that the word "cross-vertical" should be "vertical". This correction stands to correct the original article.

The original article can be found online at https://doi.org/10.1007/s11069-018-3477-7.

Indrajit Ghosh

indraghosh06@gmail.com

Nabajit Chakravarty

nabajit_c@yahoo.com

1 Department of Basic Sciences, College of Engineering and Management Kolaghat, East Medinipur, West Bengal 721171, India

2 Meteorological Office, Imphal, New ATS Building, Imphal International Airport, Imphal West 799140, India 